\title{
LA PROBLEMÁTICA DE LOS PUEBLOS AMAZÓNICOS DESDE LA PERSPECTIVA DE LA DOCTRINA SOCIAL DE LA IGLESIA
}

\author{
The Problematic of the Amazonian Peoples from the Perspective of the \\ Social Doctrine of the Church
}

Flavio Gutiérrez Velasco*

Nuccia Seminario Hurtado**

Recepción: 04-11-2018

RESUMEN

Aceptación: 07-11-2018

El presente artículo aborda la problemática de los derechos humanos de los pueblos amazónicos del Perú, que no se respetan debido fundamentalmente a una política neoliberal, consumista y que lo único que busca es la ganancia y el lucro. Esta problemática es abordada desde una perspectiva humanista y de la doctrina social de la Iglesia, en el marco de la visita que hiciera al Perú el Papa Francisco del 18 al 21 de enero del 2018.

\section{Palabras clave}

Pueblos amazónicos, derechos fundamentales, minorías, cultura de descarte, interculturalidad.

\begin{abstract}
This paper deals with the problems regarding the human rights of the Amazonian peoples of Peru, which are not respected mainly due to a neoliberal and consumeristic policy that seeks only profit. This problem is approached from a humanistic and social doctrine of the Churchu perspective, in the context of the visit that Pope Francis made to Peru from January 18 to 21, 2018.
\end{abstract}

\section{Keywords:}

Amazonian peoples, fundamental rights, minorities, culture of discarding, interculturality.

* Universidad Femenina Sagrado Corazón (UNIFE): flaviogutierrezv@unife.pe

** Coordinadora General del Círculo de Estudios en Ambiente y Desarrollo Sostenible (CEADES) de la Universidad Femenina del Sagrado Corazón (UNIFÉ).: nuccia_sh@hotmail.com 


\section{INTRODUCCION}

Los pueblos indígenas están viviendo en sus tierras antes que vinieran los colonizadores de otros lugares y, a pesar del tiempo transcurrido, conservan sus características culturales, económicas y políticas, que son manifiestamente distintas de las de los demás sectores del país (Aroca, 1996, p.19)

En el Perú, los pueblos indígenas en su totalidad están ubicados en la Amazonía Peruana, según señaló el Instituto Nacional de Estadística e Informática ${ }^{1}$, superando la cifra de 330 mil habitantes. Por ello, es preciso incidir que en dicho territorio su población está sumergida en una serie de conflictos socioculturales que impiden que sus integrantes puedan gozar de la vigencia efectiva de sus respectivos derechos fundamentales.

En el presente trabajo abordaremos los principales problemas que viven nuestros pueblos amazónicos, como son la falta de diálogo intercultural, la minería ilegal, la educación intercultural bilingüe, la trata de personas y los pueblos indígenas en situación de aislamiento, problemas que impiden el progreso y desarrollo sociocultural de estos hermanos nuestros. Esta problemática será vista a la luz de nuestra legislación vigente y de la doctrina social de la Iglesia, especialmente del magisterio del Papa Francisco, para proponer algunas alternativas de solución.

\section{PROBLEMÁTICA DE LA AMAZONIA}

\subsection{La falta de diálogo intercultural}

El papa Francisco a la llegada a Puerto Maldonado, en uno de sus emblemáticos discursos, expresó que el Perú es "un rostro plural, de una variedad infinita y de una enorme riqueza biológica, cultural, espiritual." (Francisco, 2018, p.21). Como lo denotó el actual Sumo Pontífice, una particularidad del territorio peruano es su diversidad cultural y lingüísticay, a su vez, esta conlleva una falta de diálogo intercultural, siendo esta la primera problemática en la que se ven sumergidos los pueblos originarios provenientes de la Amazonía Peruana.

La interculturalidad es un concepto atribuido de las ciencias sociales, enfocada en el estudio de la comunicación de dos o más culturas de un determinado espacio geográfico. A propósito de ello, el Ministerio de Cultura señaló que "cada grupo étnicocultural tiene formas diversas de pensar, sentir y hacer, lo que incluye sus propias formas de concebir lo que es bueno o malo, lo que conduce su bienestar o sus formas de comunicarse y expresarse." (2016, p. 11)

Otra definición de interculturalidad la concibe como el respeto que existe entre una y otra cultura, haciendo hincapié en la dinamización de esta, reflejada en una determinada nación, pues, conlleva una unión de distintas costumbres, hábitos y usos. $^{2}$ Asimismo, la interculturalidad puede ser concretizada como un "choque" de diferentes culturas, en el caso del

1 Según el Instituto Nacional de Estadística e Informática (INEI: 09 de agosto del 2016) la población indígena de la Amazonía peruana asciende a 932,975 habitantes, siendo el 52,2\% hombres y el 47,8\% mujeres. Por grupos de edad, el 47,5\% son menores de 15 años, el 50,6\% tiene entre 15 y 64 años y el $1,9 \%$ tiene más de 64 años de edad.

2 Entrevista realizada el 21 de junio de 2018 a Wilmer Castillo Gamarra. Intérprete de quechua ancashino por el Ministerio de Cultura. Relator que contribuyó a la traducción de castellano a quechua ancashino en la sentencia del expediente $N^{\circ}$ 00889-2017-PA/TC del Tribunal Constitucional Peruano. 
Perú este problema es abordado por la falta de comunicación entre los pueblos amazónicos y el Estado Peruano. ${ }^{3}$

En ese sentido, el denominado fenómeno intercultural "(...) deberá buscar objetivos comunes para asî obtener ciertos logros, en forma más eficaz, aunque con previa selección de los elementos culturales que se combinan o convergen a fin de obtener mejores calidades de vida a favor de los actores involucrados." (Instituto Nacional de Desarrollo de Pueblos Andinos, Amazónicos y Afroperuanos, 2010, p.31).

Por ello, actualmente, las diferencias culturales y lingüísticas son consideradas brechas principales para el desarrollo progresivo humano de los miembros de quienes conforman la Amazonía Peruana, ya que, aquellas diferencias impiden que se fomente un diálogo de entendimiento entre ambas partes: los pueblos amazónicos y el Estado Peruano.

A raíz de ello, podemos identificar que el Estado Peruano no garantiza la vigencia efectiva del derecho a la identidad cultural consagrada en nuestra Constitución Política de 1993 (CP) (art 2, inc 19) y en la Declaración Americana sobre los derechos de los Pueblos Indígenas ${ }^{5}$, acto declarativo del cual el Perú es parte.

\subsection{La minería ilegal}

La minería ilegal es definida como la "actividad minera ejercida por personas naturales o jurídicas, o grupos de personas organizadas para ejercer dicha actividad, (...) sin cumplir con las exigencias de las normas de carácter administrativo, técnico, social y medioambiental que rigen dichas actividades, o que se realiza en zonas en las que esté prohibido su ejercicio."

Cabe denotar que el Papa Francisco, resaltó el inmenso problema que sufre la Amazonía a causa de la minería ilegal señalando que "la defensa de la tierra no tiene otra finalidad que no sea la defensa de la vida. Sabemos del sufrimiento que algunos de ustedes padecen por los derrames de hidrocarburos que amenazan seriamente la vida de sus familias y contaminan su medio natural." (Francisco, 2018, p.23)

Se debe mencionar que la minería ilegal es uno de los principales problemas existentes en la Amazonía Peruana, ya que las consecuencias repercuten de manera negativa en la población y en sus respectivos territorios, pues, asolan el espacio geográfico, contaminan el medio ambiente afectando a la salud de los miembros de las respectivas comunidades. Por ejemplo: En Puerto Maldonado, con la respiración de mercurio y metales, "el 60\% de los peces consumidos tienen niveles de mercurio superiores a los límites permitidos para la salud humana, (...) y, también se determinó que el $78 \%$ de los adultos evaluados tienen niveles de mercurio en el cabello tres veces superiores a los límites máximos

3 Entrevista realizada el 21 de junio de 2018 a Janeth Jane Gonzales Puyenti, intérprete y traductora asháninca acreditada por el Ministerio de Cultura del Perú, mediante Resolución Viceministerial № 002-2013- VMI-MC.

4 "Toda persona tiene derecho a su identidad étnica y cultural. El Estado reconoce y protege la pluralidad étnica y cultural de la Nación".

5 Declaración Americana sobre los derechos de los Pueblos Indígenas. Aprobada en la segunda sesión plenaria, celebrada el 14 de junio de 2016. Artículo XIII, inciso 3.- Los Pueblos Indígenas tienen derecho a que se reconozcan y respeten todas sus formas de vida, cosmovisiones, espiritualidad, usos y costumbres, normas y tradiciones, formas de organización social, económica y política, formas de transmisión del conocimiento, instituciones, prácticas, creencias, valores, indumentaria y lenguas, reconociendo su interrelación, tal como se establece en esta Declaración. 
permitidos" (Ministerio del Ambiente, 2016, p.2), destruyendo su hábitat y denigrando su salud.

Ante dicha exasperación, el Estado Peruano ha tratado de brindar algún tipo de soporte para erradicar toda actividad derivada de la minería ilegal; pues, "en los últimos meses los operativos de interdicción se han incrementado, pero no responden a una estrategia articulada para desplazar de manera definitiva a la minería ilegal (...), por ejemplo, en Madre de Dios, aún sigue ejerciéndose esta actividad." (Sociedad Peruana de Derecho Ambiental, 2014, p.183)

Definitivamente la minería ilegal trae consigo efectos negativos, por ello, podemos destacar que vulnera los derechos a la salud (CP art 7$)^{6}$, identidad cultural (CP art 2, inc 19), libre desarrollo (CP art 2 , inc 1$)^{7}$, paz y tranquilidad (CP art 2 , inc 22$)^{8}$, todos estos consagrados como derechos fundamentales en nuestra Carta Magna vigente.

\subsection{Educación Intercultural Bilingüe}

El Ministerio de Educación expresó que en el Perú predominan cuarenta y siete lenguas originarias, de las cuales en la región selva se hablan alrededor de cuarenta y tres (2013), ${ }^{9}$ catalogadas como lenguas vitales y en uso.

Según García y Ruíz "todas las poblaciones y culturas interaccionan unas con otras permanentes, por lo que se debe educar al ciudadano en relación a las circunstancias socioculturales del entorno en el que vive. De ahí que la educación intercultural sea clave educativa en la formación y preparación del individuo." (2015, p.387)

A raíz de ello, el Estado Peruano ha elaborado una serie de políticas públicas enfocadas en garantizar la educación desde dos cosmovisiones: intercultural y lingüística; a los miembros de los pueblos originarios, empero, dichas políticas públicas no han sido suficientes para cumplir con todos los estándares. Como expresó el Papa Francisco: "la escuela y la educación de los pueblos originarios debe ser una prioridad y compromiso del Estado; compromiso integrador e inculturado que asuma, respete e integre como un bien de toda la nación su sabiduría ancestral" (Francisco, 2018, p.26)

En la Amazonía Peruana se han detectado dos problemas sobre la educación intercultural bilingüe: a) solamente hay docentes bilingües y los respectivos materiales educativos en las siguientes lenguas amazónicas: awajún, ashaninka, shipibo-konibo, shawi, matsigenka, nomatsigenga, kakinte, achuar, wampis, urarina, cashinahua, harakbut, matsés, jaqaru, yine, ese eja, kakataibo, kandozi, chapra, yanesha y murui-muinani (Ministerio de Educación, 2018), constituyéndose como una primera

6 "Todos tienen derecho a la protección de su salud, la del medio familiar y la de la comunidad, así como el deber de contribuir a su promoción y defensa".

7 "Toda persona tiene derecho a la vida, a su identidad, a su integridad moral, psíquica y física y a su libre desarrollo y bienestar".

8 "Toda persona tiene derecho a la paz, a la tranquilidad, al disfrute del tiempo libre y al descanso, así como a gozar de un ambiente equilibrado y adecuado al desarrollo de su vida".

9 Lenguas Amazónicas: achuar ,amahuaca ,arabela, ashaninka ,awajún ,bora ,capanahua ,cashinahua, chamicuro, ese eja ,harakbut ,iñapari ,iquitu, isconahua, kakataibo ,kakinte ,(caquinte) ,kandozi-chapra kukama-kukamiria madija (culina) ,maijuna ,matsigenka, matses, muniche ,murui-muinani nanti nomatsigenga, ocaina ,omagua, resígaro, secoya ,sharanahua, shawi ,shipibo-konibo, shiwilu, taushiro ,tikuna (ticuna) ,urari na ,wampis ,yagua, yaminahua, yanesha ,yine ,yora (nahua). 
brecha para promover la educación intercultural bilingüe de todos los miembros de los pueblos originarios situados en la Amazonía Peruana; b) seguido a ello, los docentes, en su mayoría jóvenes, no dominan bien la lengua originaria o desconocen la cultura, constituyéndose una segunda brecha para impartir una educación de calidad a los miembros que integran los pueblos amazónicos (Puyenti 2018).

Soto expresa que "el uso de la lengua es relevante, si se desprende de un contexto que dé las condiciones que propicien la interacción en dicha lengua. Por otro lado, una lengua es inherente a los participantes si estos han incorporado normas de interacción" (2008, p.23), por ello, las faltas de capacitaciones para docentes interculturales bilingües y materiales de enseñanza, hechos por el Ministerio de Educación, constituyen un impedimento para el goce efectivo de la educación intercultural bilingüe.

Al haber analizado detalladamente dicha problemática, se ha identificado la vulneración de los siguientes derechos fundamentales: a la educación (CP art $15)^{10}$, a recibir educación en una lengua originaria (CP art 17$)^{11}$ y a la identidad cultural (CP art 2, inc 19), puesto que el Estado Peruano no brinda una educación intercultural bilingüe de calidad a los miembros de los pueblos amazónicos.

\subsection{Trata de personas}

La trata de personas es definida como "la captación, transporte, traslado, acogida o recepción de personas, recurriendo a la amenaza, al uso de la fuerza u otras formas de coacción (...) para obtener el consentimiento de una persona que tenga autoridad sobre otra, con fines de explotación." ${ }^{12}$

El Código Penal Peruano en concordancia con los lineamientos del Protocolo de Palermo, tipifica la trata de personas en la Ley $N^{\circ}$ 28950: Ley contra la Trata de Personas y el Tráfico Ilícito de Migrantes, como un delito contra la libertad. La trata de personas se ve reflejada en la explotación laboral, sexual, reclutamiento forzoso, tráfico de órganos y matrimonio servil, con mayor predominio en la Amazonía Peruana. A raíz de ello, el Sumo Pontífice actual expresó que "la trata de personas: la mano de obra esclava o el abuso sexual. La violencia contra las adolescentes y contra las mujeres es un clamor que llega al cielo. Siempre me angustió la situación de los que son objeto de las diversas formas de trata de personas" (Francisco, 2018, p.24)

Con respecto a la trata de personas en la explotación laboral, según la ONG Capital Humano y Social Alternativo "existe una modalidad de trata con fines de explotación laboral que difícilmente puede controlarse, esa ocurre en las plantaciones de coca" (2016, p.40), es más común ver a menores en trabajos ligados a las minas, por ello tras la realización de dichos trabajos forzosos genera el fenómeno llamado "explotación infantil" en la Amazonía Peruana.

El departamento en el que más predomina la trata de personas es Madre de Dios, "precisamente en la Pampa donde

10 "La educación tiene como finalidad el desarrollo integral de la persona humana. (...)"

11 "El Estado Peruano (...) fomenta la educación bilingüe e intercultural, según las características de cada zona. Preserva las diversas manifestaciones culturales y lingüísticas del país. Promueve la integración nacional".

12 Protocolo para prevenir, reprimir y sancionar la trata de personas, especialmente mujeres y niños, que complementa la Convención de las Naciones Unidas contra la Delincuencia Organizada Transnacional. Artículo 3, a), conocido como Protocolo de Palermo. 
abundan los llamados prostibares, lugares insalubres, donde explotan a las mujeres. Aquí son llamadas 'ficheras', mujeres que beben y bailan con los clientes, soportando sus tocamientos y accediendo a los llamados pases $^{\prime 13}$, que en lenguaje coloquial significa "mantener relaciones sexuales con el cliente". A su vez esta problemática social se ve reflejada en otros poblados de Madre de Dios, "en la zona minera de Huepetuhe, Pukiri y Delta, donde se calcula que 400 púberes y adolescentes son explotadas sexualmente en las cantinas, llamadas localmente prostíbares." (Ministerio del Ambiente, 2016, p.2)

Lamentablemente existe poca información sobre el seguimiento de las personas que fueron víctimas de explotación sexual, ya que no existen registros consolidados, y en su mayoría por temor a no denunciar en las comisarías correspondientes. ${ }^{14}$

En el caso de trata de personas, podemos identificar que las víctimas sufren la vulneración del derecho a la libertad (CP art 2, inc 24) ${ }^{15}$, a la integridad $(\mathrm{CP} \text { art } 2 \text {, inc } 1)^{16}$, a la dignidad (CP art 1$)^{17}$, a la paz y tranquilidad (CP art 2, inc 22) ${ }^{18}$. Por ello el Estado Peruano está tratando de erradicar dicha problemática, realizando fiscalizaciones en los prostibares. El problema se agranda aún más, cuando las víctimas son menores de edad.

\subsection{Pueblos Indígenas en situación de aislamiento}

Los pueblos indígenas en situación de aislamiento, son miembros de un determinado pueblo originario "que no han desarrollado relaciones sociales sostenidas con los demás integrantes de la sociedad nacional o, de haberlo hecho, optaron por descontinuarlas", (Ministerio de Cultura, 2016, p.7), también, son pueblos o segmentos de pueblos originarios "que no mantienen contactos sostenidos con la población mayoritaria no indígena, y que suelen rehuir todo tipo de contacto con personas ajenas a su pueblo". (Comisión Interamericana de Derechos Humanos, 2013, p.4)

Según Wuster:

Se les ha dominado de muchas maneras, desde «calatos» hasta «pueblos libres». Algunas personas niegan su existencia en base a la idea de que nadie escapa a la modernización; otros expresan actitud paternalista, promoviendo la aceleración de su integración a la sociedad nacional para poner freno a su «nomadismo», entendido este como forma «primitiva»e inadecuada de vivir (2003, p.35)

13 AMERICA TV. Cuarto Poder. Video: "Trata de personas: la dramática situación en La Pampa" del 26 de setiembre de 2016. Recuperado de: http://www.americatv.com.pe/noticias/actualidad/trata-personas-dramatica-situacion-pampa-n248400

14 Unos 212 niños han sido víctimas de trata de personas en selva peruana, publicado el 9 de mayo de 2012 por RPP. Recuperado de: http://rpp.pe/peru/actualidad/unos-212-ninos-han-sido-victimas-de-trata-de-personas-en-selva-peruana-noticia-480339

15 "Toda persona tiene derecho a la libertad y a la seguridad personales. En consecuencia: b. No se permite forma alguna de restricción de la libertad personal, salvo en los casos previstos por la ley. Están prohibidas la esclavitud, la servidumbre y la trata de seres humanos en cualquiera de sus formas".

16 "Toda persona tiene derecho a la vida, a su identidad, a su integridad moral, psíquica y física y a su libre desarrollo y bienestar".

17 "La defensa de la persona humana y el respeto de su dignidad son el fin supremo de la sociedad y del Estado".

18 "Toda persona tiene derecho a la paz, a la tranquilidad, al disfrute del tiempo libre y al descanso, así como a gozar de un ambiente equilibrado y adecuado al desarrollo de su vida". 
El Papa Francisco hace mención a dicha minoría expresando que "son los más vulnerables de entre los vulnerables. El rezago de épocas pasadas les obligó a aislarse hasta de sus propias etnias, emprendieron una historia de cautiverio en los lugares más inaccesibles del bosque para poder vivir en libertad." (Francisco, 2018, p.24).

El Ministerio de Cultura señaló que alguna de las actividades principales de dicha minoría es la realización de "desplazamientos estacionales en amplios territorios, aprovechando recursos del bosque mediante la caza, pesca y recolección" (2013), por ello son vulnerables ante su salud por el constante contacto con virus y bacterias.

En el Perú, los pueblos indígenas en situación de aislamiento se encuentran en su mayoría en la Amazonia Peruana. Por ello, muchos expertos realizan trabajos de investigaciones sobre este tema. Por ejemplo se encargan de "diseñar una estrategia de trabajo a largo plazo para atender la presencia de indígenas mashco piro en situación de aislamiento voluntario en el departamento de Madre de Dios ${ }^{19}$, asimismo, el "Ministerio de Cultura (...) con diferentes sectores del Estado se reúne para coordinar acciones conjuntas de protección de los Pueblos Indígenas en Aislamiento (...), que se sitúan en las Reservas Territoriales Isconahua, Muranahua, Mashco Piro y Madre de Dios (Ministerio de Cultura, 2014).

El Estado Peruano ha elaborado una serie políticas y estrategias para garantizar los derechos fundamentales de los pueblos amazónicos en aislamiento, empero, aún sigue constituyéndose en una brecha para el fomento del diálogo intercultural, problemática ya desarrollada en el presente acápite.

\section{LOS DERECHOS HUMANOS DE LOS PUEBLOS AMAZÓNICOS A LA LUZ DE LA DSI}

Hoy resulta evidente que los integrantes de las diversas etnias amazónicas son sujetos de derechos, sin discriminación alguna en razón de su raza, cultura, sexo... (CP art 2, inc 2); pero no siempre fue así: durante la época colonial fue intenso el debate sobre si los indígenas tenían alma o no, imponiéndose aquella que defendía la humanidad de los indios, cuya figura más representativa fue Bartolomé de las Casas (Sevilla 1474-Madrid 1556)20, religioso dominico, símbolo de la defensa de que los indígenas son seres humanos, como cualquier otro europeo.

Nos, que, aunque indignos ejercemos en la tierra el poder de nuestro Señor... consideramos sin embargo que los indios son verdaderos hombres y que no solo son capaces de entender la fe católica, sino que, de acuerdo con nuestras informaciones, se hallan deseosos de recibirla (citado por Albornoz).

La Iglesia católica, desde su llegada a estos territorios peruanos, tuvo como misión evangelizar a todos los indígenas. En esta tarea de llegar a los pueblos amazónicos destacaron las órdenes religiosas de los jesuitas

19 Ministerio de Cultura y expertos internacionales analizan problemática de pueblos en situación de aislamiento en Madre de Dios, publicado el 2 de marzo de 2015. Recuperado de: http://www.cultura.gob.pe/ es/comunicacion/noticia/ministerio-de-cultura-y-expertos-internacionales-analizan-problematica-de

20 De las Casas se desempeñó como defensor de los indígenas en la corte española a partir de 1555. Otra figura que luchó a favor de los indígenas fue Fray Antonio de Montesinos, también religioso dominico. 
y de los franciscanos. Los primeros evangelizaron la parte nororiental, en la zona comprendida por el río Marañón y sus afluentes, Amazonas, Napo, Ucayali parte del Huallaga; los segundos evangelizaron la Selva central fundando un convento en Huánuco en 1580. Santa Rosa de Ocopa se convirtió en el centro misionero más importante de la sierra y selva central.

La presencia de la Iglesia católica en los pueblos amazónicos sigue siendo en la actualidad el factor más importante en la defensa de sus derechos: los misioneros no sólo se limitan a predicar el evangelio, sino sobre todo a sacarlos de la ignorancia. Su acción no sólo se limita al campo religioso, sino también al campo sociocultural, muchas veces asumiendo tareas que son propias del Estado.

Desde sus inicios, la Iglesia católica se preocupó porque estos pueblos sean evangelizados en su lengua materna. Así los concilios limeños de 1551-1552 y 1567, legislaron, entre otras cosas, la obligación de los sacerdotes de aprender las lenguas aborígenes para instruir a los indígenas. El tercer concilio limeño (1582) ordenó la elaboración de un catecismo único en español, quechua y aymara.

A partir del Concilio Vaticano II y de las Conferencias Episcopales Latinoamericanas hay un cambio en la manera de entender la evangelización: esta es concebida como una lucha por los derechos humanos, para lo cual la iglesia tiene que inculturizarse. En el Perú, ya en 1971 se realizó una reunión pastoral de obispos, sacerdotes, agentes de pastoral, en la cual surge la idea de una "Iglesia amazónica", inculturada en los pueblos amazónicos, como también se ve la necesidad de que los agentes de pastoral aprendan las lenguas originarias, sus cosmovisiones, su cultura. En esta perspectiva el Papa Francisco, ante la petición de algunos obispos latinoamericanos, ha convocado al Sínodo para la Amazonía para octubre del 2019, que ya está en pleno proceso de preparación ${ }^{21}$.

Sentada la premisa indiscutible de que los pobladores de las diversas etnias amazónicas son seres humanos con derechos inalienables y la premisa de que son hijos de Dios, se deben respetar y cautelar todos sus derechos. La perspectiva teológica de los derechos humanos deriva de la concepción antropológica de que todo ser humano es "imagen y semejanza de Dios" (Gn 1,27), su dignidad le proviene, pues, de ser creado por Dios (Santo Domingo: SD 164-168), por lo cual "toda violación de los derechos humanos contradice el plan de Dios y es pecado" (SD 164). Esta perspectiva teológica asume plenamente la perspectiva humanista de los derechos humanos (Declaración universal de los derechos humanos, proclamada por la ONU, Constitución Política del Perú, arts. 1-3).

Si resulta tan evidente que todo ser humano, sin ninguna exclusión, es sujeto de derechos, nos preguntamos cómo es posible que no se respeten muchos de estos derechos de nuestros pueblos amazónicos. La respuesta hay que buscarla en la ideología neoliberal, con su perspectiva eminentemente economicista, consumista, competitivista, que ve al hombre como un "homo faber", que produce para consumir; se valora al hombre por su eficacia en el producir. En esta perspectiva se margina al niño, al

21 Ya existe un documento preparatorio para este sínodo panazónico: "Amazonía: nuevos caminos para la Iglesia y para una ecología integral", donde las encíclicas "Evangelii Gaudium" y la "Laudato si" del Papa Francisco, son fuentes importantes para abordar los temas que se tratarán en este sínodo. 
anciano, al enfermo... que no producen y, por lo tanto, habría que descartarlos. Estamos frente a lo que el Papa Francisco, denomina la "Cultura del descarte", que desecha todo lo que no sirve a los intereses de la clase capitalista:

La tierra es tratada dentro de esta lógica. Los bosques, ríos y quebradas son usados, utilizados hasta el último recurso y luego dejados baldíos e inservibles. Las personas son tratadas también con esta lógica: son usadas hasta el cansancio y después dejadas como 'inservibles' (Francisco 2018, p. 30).

Frente a la depredación de la naturaleza, de la "casa común", de la "madre tierra" y todos los problemas conexos con ella, como es la minería ilegal, se hace necesario reproponer la doctrina cristiana que ve la naturaleza como un don de Dios o de la concepción de nuestros pueblos aborígenes que ven en ella la "madre tierra" que nos proporciona el sustento, como también del llamado a hacer un uso racional de los recursos ${ }^{22}$. Francisco, en su visita a los pueblos amazónicos, les expresó que había ido para unirse a sus desafíos y reafirmar con ellos "una opción sincera por la defensa de la vida, defensa de la tierra y defensa de las culturas" (2018, p.22).

Ante la violación del derecho a su identidad cultural, a expresarse en su propia lengua (CP art 2, inc 19) se deben proponer políticas de estado encaminadas a la defensa de este derecho, a seguir fomentando la formación de institutos donde se enseñe estas lenguas nativas y se formen docentes bilingües para que puedan enseñar a los nativos en sus propias lenguas. Otro aspecto de este problema es el riesgo de desaparición de la "reserva cultural", expresión de los neocolonialismos, contra los que todos estamos obligados a luchar. Francisco recuerda que la "desaparición de una cultura puede ser tanto o más grave que la desaparición de una especie animal o vegetal" (LS 145). El Papa, en su mensaje a los pueblos amazónicos, les expresa la necesidad de dialogar para "rescatar la cultura, lengua, tradiciones, derechos y espiritualidad que le son propios y que el camino para salir de la exclusión y discriminación es el "diálogo intercultural" (2018, p. 23; LS 146) 23 .

Otro problema que se tiene que denunciar con valentía que denigra a la persona, especialmente a las mujeres, es la "trata de personas", convirtiendo a adolescentes y mujeres en objetos sexuales y de consumo. "La violencia contra las adolescentes y contra las mujeres es un clamor que llega al cielo" (Francisco, 2018, p.24). Es aquí donde especialmente se tiene que hacer presente la acción evangelizadora de la Iglesia y su opción preferencial por los débiles y oprimidos (Puebla 733) o, para expresarlo con palabras de nuestros obispos latinoamericanos, ser "voz de aquellos que no tienen voz".

El rol que desempeña la Iglesia Católica en el tema de la trata de personas es fundamental: existen numerosas congregaciones religiosas, asociaciones, movimientos como la Red KAWSAY Perú, que ofrecen ayuda, apoyo, acogida, asistencia para combatir esta nueva esclavitud, específicamente es la Comisión Episcopal para la Acción Social (CEAS),

22 El Papa Francisco dedica la encíclica "Laudato si" a recuperar esta imagen de la tierra como nuestra "casa común".

23 El Papa Francisco ha dedicado la Encíclica "Evangelii gaudium" (sobre el anuncio del evangelio en el mundo actual) a cómo se debe anunciar el evangelio hoy, donde aborda con detenimiento el tema de la inculturación del evangelio y toda una teología de la inclusión (no a una economía de exlusión: 53-54) 
de la Conferencia Episcopal Peruana, la encargada de velar por este problema (Conferencia Episcopal Peruana, 2013)

Frente a esta problemática de nuestros pueblos amazónicos, los obispos latinoamericanos, principalmente en las dos últimas conferencias de Santo Domingo y Aparecida, han sido reiterativos en comprometerse a denunciar toda violación de los derechos humanos de nuestros pueblos afroamericanos e intensificar su acción pastoral a través de una presencia activa en estos pueblos. Nuestros obispos son enfáticos al expresar su compromiso con los pueblos indígenas en defensa de sus culturas, de una educación intercultural bilingüe y la defensa de sus derechos:

Como discípulos y misioneros al servicio de la vida, acompañamos a los pueblos indígenas y originarios en el fortalecimiento de sus identidades y organizaciones propias, la defensa del territorio, una educación intercultural bilingüe y de defensa de sus derechos. Nos comprometemos también a crear conciencia en la sociedad acerca de la realidad indígena y sus valores, a través de los medios de comunicación social y otros espacios de opinión. A partir de los principios del Evangelio apoyamos la denuncia de actitudes contrarias a la vida plena en nuestros pueblos originarios, y nos comprometemos a proseguir la obra de evangelización de los indígenas, así como a procurar los aprendizajes educativos y laborales con las transformaciones culturales que ello implica (Aparecida 530).

No debemos desmayar en la lucha por la defensa de los derechos humanos, que es la nueva forma de evangelizar, tarea en la cual se tiene que comprometer a la población. El Papa Francisco concluye su discurso a los pueblos amazónicos invitándolos a que sean ellos quienes moldeen culturalmente las Iglesias locales amazónicas y no a la inversa, que se les imponga una cultura desde fuera; les pide que ayuden a sus obispos y a los misioneros y misioneras a "plasmar una iglesia con rostro amazónico y una iglesia con rostro indígena (2018, p.28).

\section{CONCLUSIONES}

La Amazonía peruana se encuentra sumergida en una serie de problemas sociales y culturales que impiden que los habitantes de estos pueblos originarios puedan ejercer sus derechos fundamentales.

La actual problemática de la Amazonía Peruana constituye un impedimento para que estos pueblos originarios puedan ejercer la vigencia efectiva de sus derechos fundamentales.

La presencia del Estado peruano en estos pueblos amazónicos está muy empobrecida, no asume plenamente su papel de tutelar los derechos de los pueblos amazónicos, no obstante existir una legislación pertinente destinada a tutelar estos derechos fundamentales.

El Papa Francisco, a su llegada a la Amazonía Peruana detectó que sus principales problemas son: falta de diálogo intercultural, minería ilegal, educación intercultural bilingüe, tratas de personas y pueblos indígenas en situación de aislamiento.

Los derechos humanos de los pueblos amazónicos se fundamentan en la visión antropológica-teológica de que el varón y la mujer han sido creados como "imagen y semejanza de Dios". 
La Iglesia católica peruana tiene muy clara su misión evangelizadora en nuestros pueblos indígenas, que se evidencia en su compromiso concreto por hacer que se respeten esos derechos, supliendo muchas veces a la tarea que es propia del Estado.

\section{REFERENCIAS}

Albornoz Peralta, O. (s.f.). Justificación de la conquista y dominación de los indígenas americanos. Obtenido de https://www.uv.es/ pla/solidaritat/ justconq.htm.

Alternativo, O. C. (2017). La Trata de personas en el Perú. Obtenido de http://www.chsalternativo.org/ trata-de-personas-en-el-peru/682trata-2/file.

Ambiental, S. P. (2014). La realidad de la minería ilegal en países amazónicos. Lima.

Ambiente, M. d. (2013). Minería ilegal. Obtenido de http://www.minam.gob. pe/prensa/wp-content/uploads/ sites/44/2013/12/dialogo-con-laprensa-2_Minereia_ilegal.pdf .

Aparecida. V Conferencia General del Episcopado Latinoamericano y de El Carbie. (2007). Lima: Paulinas.

Arica, J. (1996). Derechos humanos y pueblos indígeneas de la Amazonía Peruana. Lima: Centro Amazónico de Antropología y Aplicación de práctica.

Castillo Gamara, W. (21 de junio de 2018). (N. Seminario Hurtado, Entrevistador)

Constitución Política del Perú. (1993).

Cultura, M. d. (2016). Los pueblos indígeneas en situación de aislamiento y contacto inicial de la Amazonía Peruana: mecanismos para la protección de sus derechos . Obtenido de https:// centroderecursos.cultura.pe/sites/ default/files/rb/pdf/PUEBLOS-\%20 INDIGENAS-EN-AISLAMIENTO-YEN-CONTACTO-INICIAL.pdf.

Educación, M. d. (2013). Documento Nacional de Lenguas Originarias del Perú. Obtenido de http://www2. minedu.gob.pe/filesogecop/DNLversion\%20final\%20WEB.pdf.

Educación, M. d. (2018). Obtenido de http://www.minedu.gob.pe/n/ noticia. php?id $=46749$.

Educación, M. d. (2018). MINEDU exhibe alfabetos oficiales y materiales educativos. Obtenido de http:// busquedas.elperuano.pe/ normaslegales/decreto-legislativoque-establece-disposicionesp a r a - e l - proc - d e c r e t o legislativo-n-1 105-778570-2/.

Francisco, P. (2015). Laudato si. Cuidar la madre tierra. Carta encíclica sobre el cuidado de la casa común. Lima: Ediciones Paulinas.

Francisco, P. (2018). El Papa Francisco en el Perú. Un mensaje de esperanza. Lima: Fondo Editorial.

García, M y Ruiz, M. (2015). Interculturalidad clave educativa para la formación del ciudadano en contexto digital. En Educación, Desarrollo y Cohesión Social. Cuenca: Universidad de Castilla- La Mancha.

Humanos, C. I. (2013). Pueblos indígenas en aislamiento voluntario y contacto inicial en las Américas: recomendaciones para el pleno respeto 
a sus derechos humanos. Obtenido de http://www.oas.org/es/cidh/ indigenas/docs/pdf/informepueblos-indigenas-aislamientovoluntario.pdf .

Instituto Nacional de Desarrollo de Pueblos Andinos, A. y. (2010). Aportes para un enfoque intercultural. Lima: Punto Grafía.

Peruana, C. E. (2013). No a la trata de personas y tráfico de migrantes. Desafíos para la nueva evangelización. Obtenido de http://www.iglesiacatolica.org. pe/cep_especiales/2013/compartir/ material/texto-base-2013.pdf.

Peruano, D. E. (19 de Abril de 2012). Decreto Legislativo que establece disposiciones para el proceso de formalización de las actividades de pequeña minería y minería artesanal. Obtenido de http://busquedas.elperuano.pe/ normaslegales/decreto-legislativoque-establece-disposicionesp a r a - e l - p r o c - d e c r e t o legislativo-n-1 105-778570-2/.

Puyenti, J. J. (21 de Junio de 2018). (N. Seminario, Entrevistador)

Santo Domingo. IV Conferencia General del Episcopado Latinoamericano. (2005). Lima: Paulinas.

Soto, J. (2008). El currículo Intercultural Bilingue: la naturaleza humana integrada a su mundo cultural. Lima: Magisterio.

Wuster, W. (2003). Los pueblos amazónicos y las reservas indígenas. Lima: La República. 